Quantum talk: How small-group discussions may enhance students' understanding in quantum physics

Berit Bungum

The Norwegian University of Science and Technology

Department of Teacher Education

berit.bungum@ntnu.no

Maria Vetleseter Bøe

University of Oslo

Department of Physics

m.v.boe@fys.uio.no

Ellen Karoline Henriksen

University of Oslo

Department of Physics

e.k.henriksen@fys.uio.no

This is a post-print version of the article published in Science Education: https://onlinelibrary.wiley.com/doi/abs/10.1002/sce.21447 


\title{
Quantum talk: How small-group discussions may enhance students' understanding in quantum physics
}

\begin{abstract}
Quantum physics challenges our views of the physical world and describes phenomena that cannot be directly observed. The use of language is hence essential in the teaching of quantum physics. With a sociocultural view of learning, we investigate characteristics of pre-university students' small-group discussions and their potential for enhancing understanding of quantum physics. The empirical data are 96 small-group discussions about two fundamental dilemmas: whether light can be both waves and particles, and whether the cat in Schrödinger's thought experiment can be considered to be both dead and alive. The discussions were analyzed by means of a framework of four categories, grouped as productive and non-productive for learning, where 'productive' means that students build constructively on each other's utterances and take the peers' ideas into account. Results show that a total of $70 \%$ of the discussions were productive, indicating that small-group discussions have a potential for enhancing understanding in quantum physics. This potential is constituted by leading students to (i) articulate conceptual difficulties, (ii) deepen their understanding through exchange of views and (iii) formulate new questions. The paper concludes with a discussion on how the learning potential of small-group discussions may be realized by combining dialogic and authoritative approaches.
\end{abstract}

\section{INTRODUCTION AND AIM}

Language is a key aspect of learning in science. The close connection between developing understanding of science concepts and expressing that understanding in words is emphasized by a number of scholars (e.g. Lemke, 1990; Mercer, 2004; Vygotsky, 1986). The use of language is 
important for learning as well as an essential part of the knowledge itself. As Lev Vygotsky expressed it: "Thought is not merely expressed in words; it comes into existence through them" (Vygotsky, 1986, p. 218). Accordingly, learning science is said to involve learning to talk science (Lemke, 1990). In line with this view, classroom talk during science teaching has been analyzed both empirically and theoretically. In particular, Mortimer and Scott (2003) investigated different kinds of discursive classroom interactions and showed how authoritative teacher talk and dialogues based on students' ideas play complementary roles and are both important in the learning process. Still, the authors argue, science classroom teaching remains dominated by authoritative approaches.

Quantum physics is a part of physics that may benefit from teaching involving more dialogic approaches because it describes sub-microscopic phenomena in ways that we cannot observe, and that fundamentally break with our experiences and the classical view of the physical world. On university level, research has shown that even if physics students may master the mathematical technicalities of quantum mechanics, their conceptual understanding is often fragmented (see e.g. Hadzidaki, 2008). A recent review undertaken by Krijtenburg-Lewerissa, Pol, Brinkman, and van Joolingen (2017) shows that there is a lack of empirical evidence of which teaching strategies promote understanding in quantum physics. They call for more research on strategies that can supports students' understanding of quantum mechanics.

The present study contributes to the field by exploring the potential of small-group discussions for supporting students' learning in quantum physics in upper secondary school. Empirical data were gathered from nine classrooms where digital teaching resources developed in the ReleQuant project were used (see Bungum, Henriksen, Angell, Tellefsen, \& Bøe, 2015). These resources emphasize students' use of language in the learning process in order to support students' qualitative understanding of theories in quantum physics and their philosophical implications. Two discussion tasks in the ReleQuant resources are investigated, dealing with the thought experiment about 'Schrödinger's cat' and interpretations of the wave-particle duality of light, respectively. 
Physics teaching has traditionally been dominated by formalistic-mathematical problem-solving rather than discussions of ideas, qualitative understanding and philosophical reflection (see e. $\mathrm{g}$. Angell, Guttersrud, Henriksen, \& Isnes, 2004; Carlone, 2003, 2004; Höttecke \& Silva, 2011). Angell et al. (2004) found that teachers as well as students were satisfied with traditional physics teaching. The use of discussions may hence not fit with teachers' and students' conceptions of efficient physics teaching. Still, research has shown that student discussions may contribute to better performance in physics (Andersson \& Enghag, 2017; Chi \& Menekse, 2015; Chi, Roy, \& Hausmann, 2008; Enghag, Gustafsson, \& Jonsson, 2007; Schwartz, 1995).

The aim of the present study is not to measure learning, but rather to investigate characteristics of small-group discussions in the case of pre-university quantum physics and their potential for advancing students' qualitative understanding. The research questions are:

1) What characterizes small-group discussions in quantum physics based on the ReleQuant material, and to what extent are they productive?

2) What constitutes the potential for learning in productive small-group discussions?

With 'productive' discussions, we mean discussions where students engage actively with ideas together and build on each other's utterances in joint knowledge building. With 'potential for learning', we mean that the small-group discussions produce situations with opportunities for developing students' understanding of quantum physics further. In research question 2 , we look for patterns in the discussions that generate these opportunities.

This article starts with a review of challenges involved in learning quantum physics. It proceeds with theoretical perspectives and previous research on the use of dialogues in teaching and categorizations of student dialogues. We then present the teaching material and the student sample, and methods used for data collection and analysis. Results are presented first as a quantitative categorization of small-group discussions into four categories, using a modified version of a 
conceptual framework in sociocultural discourse analysis from Mercer (2004). These categories are used as tools for grouping discussions as productive or non-productive for learning.

Then follows a qualitative analysis, focusing on the various ways in which productive student discussions may generate learning, that is, how the learning potential is constituted. Finally, findings are discussed in terms of how small-group discussions may be used most effectively in teaching and learning upper secondary physics.

The physics content of the small-group discussions is considered in this paper only to the extent that it sheds light on how such discussions can facilitate students' learning. Results that attend more to how students understand the content as such are reported in Myhrehagen and Bungum (2016) in the case of 'Schrödinger's cat', and Henriksen, Angell, Vistnes, and Bungum (in press) in case of the nature of light.

\section{STUDENTS' CHALLENGES IN LEARNING QUANTUM PHYSICS}

A range of studies have documented students' challenges in quantum physics (Ayene, Kriek, \& Damtie, 2011; Baily \& Finkelstein, 2009; Fischler \& Lichtfeldt, 1992; Greca \& Freire, 2003; Hadzidaki, 2008; Johnston, Crawford, \& Fletcher, 1998; Kalkanis, Hadzidaki, \& Stavrou, 2003; Mahima \& Ritwick, 2017; Pospiech, 2000; Singh, 2008). They show that students often interpret quantum phenomena in classical terms, and that they have problems in understanding their non-deterministic nature. These challenges may be due to lack of consideration of philosophical aspects in the teaching of quantum physics. As Baily and Finkelstein (2010) have noted, students tend to default to an intuitively classical perspective when teaching is not explicit about the philosophical underpinning of interpretations of quantum physics. 
The interpretations of the now well established theories in quantum physics have far-reaching epistemological and ontological consequences and break with how we usually perceive the world and with what students have learnt in classical physics (see e.g. Freire, 2003). The 'Copenhagen interpretation', building on the work by Niels Bohr and Werner Heisenberg in the late 1920s, became the standard view of how quantum theory should be interpreted (see e.g. Home \& Whitaker, 2007). It entails that a physical system does not have a definite physical state prior to being measured and that quantum mechanics can only predict the probabilities that measurements will produce certain results. The Copenhagen interpretation also entails complementarity, which means that quantum objects have complementary properties (such as wave and particle behavior) which cannot be observed or measured simultaneously. Albert Einstein did not adhere to the Copenhagen interpretation but rather held a realist view. He argued that quantum physics was incomplete and that there were unknown, hidden variables that would account for the seemingly random behavior of quantum systems. Even if the Copenhagen interpretation appears to be widely accepted, several physicists and philosophers suggest that a realist view of quantum phenomena is both possible and desirable (e.g. Bunge, 2012; Cini, 2003; Forge, 2003; Lautesse, Vila Valls, Ferlin, Héraud, \& Chabot, 2015). With a realist view, quantum objects may be referred to as real objects, "quantons" (see Bunge, 2003), but with different properties than classical objects. Many have noted, however, that textbooks tend to take an instrumentalist approach, where students are merely taught how to use mathematical tools in quantum physics without going into interpretations (Baily \& Finkelstein, 2010; Cordero, 2003; Greca \& Freire, 2014).

The empirical research reported in this paper regards students' small-group discussions about the wave-particle duality of light and the thought experiment "Schrödinger' cat". With regards to the wave-particle duality, Olsen (2002) reported that Norwegian upper secondary students struggled with the wave and particle nature of light, and some students displayed clear misunderstandings such as the notion of light as particles moving in wave-shaped trajectories. The same notion has been observed among students working with earlier versions of the ReleQuant learning resources that 
form the context for investigations in the present study (see Bungum \& Tellefsen, 2016). A more common characteristic of student conceptions of the wave-particle duality of light, however, was found to be an 'uncritical duality', which entails that students describe light as having properties of both waves and particles, without reflecting on the fact that these models are contradictory in a classical sense.

The «Schrödinger's cat» thought experiment was originally presented in order to show how the concept of superposition has absurd consequences when interpreted as a dual state, since a quantum state may be linked to macroscopic entities by a physical arrangement (see e.g. Haroche, 2013; Kragh, 2002). A study by Myhrehagen and Bungum (2016) involving upper secondary physics students showed that students' interpretations range from trivial notions, for example that we cannot know whether a cat in a box is dead or alive until we open the box, to reflections that have some resemblances with physicists' interpretations of quantum physics today or through history. This includes the 'hidden variable theory', advocated by Albert Einstein. Some students also express conceptions that resemble the Copenhagen interpretation, where prior to measurement, the state of a quantum system can only be predicted by means of probabilities for certain outcomes of measurement. The system is in a 'superposition', described by a wave function that contains the possible states. It is concluded in the study that physics teaching should familiarize students with the historical context where the thought experiment was formulated, in order to help them better understand interpretations of quantum physics.

\section{DIALOGUES FOR LEARNING}

During the last few decades, dialogic teaching has emerged as a concept denoting teaching that builds on and develops students' knowledge by means of dialogue, theoretically based on Vygotsky, Bruner and Bakhtin (see e.g. Alexander, 2006; Lyle, 2008; Mortimer \& Scott, 2003). The key features 
of what we term dialogic teaching is formulated by Alexander (2006): It is collective, which means that all students should (have the opportunity to) participate, and hence the educational tasks must address and include all kinds of students in the class. It is reciprocal, which means that teachers and students listen to each other, share their viewpoints, consider each other's thoughts, and in this way develop their ideas further. This means that dialogic teaching also must be supportive, to provide for students to share their ideas freely and participate in the communication without fear of making mistakes. Further, the dialogue must be cumulative in that the each step in the process builds on the foregoing, and purposeful in that the teacher undertakes the dialogic process with specific educational goals in mind.

For classroom dialogues between a teacher and a group of students, Mortimer and Scott (2003) have described different communicative approaches, based on two dimensions: authoritative/dialogic and interactive/non-interactive. Authoritative approaches involves that the teacher brings disciplinary content into the classroom, with or without interaction by students. The attention is on the scientifically authoritative version of the topic at hand. Dialogic approaches, on the other hand, give room for exploring students' ideas, different perspectives and contradictive viewpoints. Scott, Mortimer, and Aguiar (2006) have pointed to a tension between these, and emphasized that science teaching should have a sound balance between authoritative/dialogic and interactive/non-interactive approaches. More recently, Tang (2017) has analyzed the role of metadiscourse in science teaching. Building on Lemke (1990) and others, he developed a framework of ways in which science teachers use metadiscourse to construct scientific knowledge with their students. Metadiscourse may connect a conversation to students' prior knowledge or activities (organizational metadiscourse), or signal a stance towards content of the conversation and its evidential status (evaluative metadiscourse).

This relates to how students engage with disciplinary content in productive ways when dialogues are used as a teaching approach. In an extensive review of research literature, Engle and Conant (2002) formulate four principles for learning environments that support productive disciplinary engagement 
in classroom dialogues. 'Productive disciplinary engagement' is defined as a combination of interactional aspects and ideas of what constitutes productive discourse in a content domain (Engle \& Conant, 2002). The principle problematizing content means that students are encouraged to take on intellectual problems. Teachers should encourage students' questions, proposals, challenges, and other intellectual contributions, rather than expecting that they should simply assimilate facts, procedures, and other "answers" (Engle \& Conant, 2002, p. 404). Authority as a principle means that students are given authority in defining, addressing, and resolving problems. Further, accountability means that students' intellectual work is made accountable to others and to disciplinary norms to the extent that these can be embodied in a classroom. To be accountable to others means to be responsive to others' views and take them into account in constructing their understanding. Finally, providing relevant resources means that students are provided with sufficient resources for embodiment of the other principles. It may include having sufficient time for going in depth or access to relevant information for solving the task.

Teachers may be reluctant to engage in dialogic teaching as it transfers some control of the content flow in teaching to the learners. Many research studies have described the tension between providing students with the freedom to express and explore different views and maintaining sufficient control to deliver curriculum goals (see Howe \& Abedin, 2013). However, the limited use of dialogic teaching may also be due to structural challenges teachers face when attempting to incorporate dialogues in teaching. Based on in-depth case studies, Sedova, Salamounova, and Svaricek (2014) have identified typical problems teachers encounter. Firstly, the heterogeneity of students in a normal class clashes with the core idea of dialogic teaching since it entails collective meaning-making between the teacher and the student group as a whole. Differences in ability, motivation and background knowledge make it difficult to develop students' knowledge without excluding considerable parts of the class. It is observed that when a teacher engages in a dialogic exchange of views with specific students, other students often stop paying attention (Bungum, Manshadi, \& Lysne, 2014; Sedova et al., 2014). Hence, the characteristic of dialogic teaching being 
reciprocal as described by Alexander (2006) may clash with the criterion of being collective. Sedova et al. (2014) argue that activation of all students takes place at the expense of concentration. The result is a lack of rational argumentation in classroom dialogues since most students' responses will not build on previous responses from fellow students but relate to the teacher's initial starting point.

Small-group discussions are a way of letting students express and investigate ideas in ways that attend to heterogeneity and that involve all students actively. Still, as Kirschner, Sweller, and Clark (2006) have pointed out, it is clear that unguided instructions, such as small-group discussions, in themselves cannot produce completely new knowledge within a subject area. However, research has indicated that collaborative problem solving in physics gives higher learning gains than other instructional methods (Chi et al., 2008), and that students in groups may perform significantly better in problem solving than one would expect from the most competent member of the group (Schwartz, 1995). Research has also shown that discussions function more purposefully when differing views are represented (Bennett, Hogarth, Lubben, Campbell, \& Robinson, 2010). The differing views may be represented by an initial dissimilarity of students' understanding of the science topics involved, or conflicting views presented to students as part of the discussion task.

\section{CLASSIFICATIONS OF SMALL-GROUP DISCUSSIONS}

The quantitative approach in parts of this study requires a framework for classifications of students' discussions. Mercer (2004) offers a typology of three archetypical forms of discussions: disputational, cumulative and explorative talk. Mercer builds his typology on sociocultural theory of learning and draws on Vygotsky's view that people jointly construct understanding through language (Vygotsky, 1978). In Mercer's words, "when working together, we do not only interact, we 'interthink"” (2004, p. 139). Mercer's three forms of discussions provide a tool for studying how the content and nature of dialogues are linked to their educational outcomes. Disputational talk is characterized by 
disagreement and individualized decision-making. The individual moves do not build on each other and hence do not contribute to agreement or any shared understanding. Cumulative talk are forms of discussions where participants build on each other's utterances and construct a joint body of knowledge accumulated by individual contributions. In Exploratory talk, participants engage critically with each other's ideas. Statements and suggestions are offered for joint consideration; these may be challenged in order to reach a decision or agree on a shared understanding.

Chi (2009) developed a framework of three categories of learning activities reflecting different ways students participate: active, constructive and interactive. The framework is hierarchical; interactive activities entail that more knowledge is generated than in constructive activities, which in turn generate more knowledge than active activities. Active means that the learner is doing something physically, which in discussions might be merely to repeat what is being said. This may support learning by contributing to consolidation, but does not necessarily produce new knowledge. In constructive learning activities, learners infer new knowledge, repair own faulty knowledge or restructure knowledge. Interactive learning activities mean that learners engage in substantive dialogues, where a partner's contribution is taken into account, confronted or challenged. Discourse activities are not necessarily interactive (in the sense of interaction with ideas) $\bar{T}$ even if all members of the group are actively or constructively participating in the discussion.

The framework for analysis of data in this paper has the categories from Mercer (2004) (disputational, cumulative and explorative talk) as a starting point, modified inductively from empirical data from the study. The conceptualizations of activities as active, constructive or interactive (Chi, 2009) are used in order to operationalize the categories for analysis. The framework and their operationalisations are presented as part of the method section. 


\section{THE RELEQUANT TEACHING MATERIAL}

ReleQuant is a project that combines research with development in several cycles with Educational Design Research as a methodological frame (see Bungum et al., 2015). The developed product is online learning resources in quantum physics and general relativity for physics in upper secondary school. The material is made to support teachers in realizing the curriculum for physics in Norwegian upper secondary school. The specific competence aims in the curriculum state that students in the highest level of physics (Physics 2) in year 13 should be able to

- give an account of Einstein's explanation of photoelectric effect, and give a qualitative account of how results from experiments with photoelectric effect, Compton scattering and the wave nature of particles represent a break with classical physics

and

- give an account of Heisenberg's uncertainty relations, describe the phenomena "entangled photons" and give an account of their cognitive consequences ${ }^{1}$.

(NDET, 2006)

The competence aims relate to philosophical aspects of modern physics and call for more qualitative approaches to the teaching of physics than what is normally found in a physics classroom. They are hence found to be challenging for teachers to teach (Bungum et al., 2015), although students find the topics interesting (Bøe, Henriksen, \& Angell, accepted).

\footnotetext{
1 "Epistemological consequences" might be a better translation of the term ("erkjennelsesmessige konsekvenser") used in the Norwegian version of the document.
} 
The development of teaching resources is based on a sociocultural view of learning, and emphasizes the use of language. The resources invite students to use their own language in writing tasks and small-group discussions. The material also includes video clips where students can watch physicists talking about interpretations of quantum physics, including different views on what light is. It is meant for teaching during school hours in full class with discussions in groups, and teachers are encouraged to use full class discussions and to sum up important points during students' work with the material. The material is freely available (also in English) from the web platform viten.no.

The two discussion tasks used for data collection in this paper are both results of the iterative process that characterizes Educational Design Research. The first task concerns wave-particle duality and was introduced based on earlier results from the project showing that students may hold an uncritical duality conception of light as described earlier in this paper. In order to make students reflect on the contradiction between the wave model and the particle model in a classical sense, students were given the following task:

1. Discuss with a fellow student: Is it possible to think of light as being both wave and particle?

The question is accompanied by illustrations and a short explanation in order to make the principal difference between a wave and a particle clear to students (see Figure 1). Before discussing the question, students are provided with a short video of two physicists expressing different views on the nature of light. After completing the discussion task, the students watch another short video where the physicists explicitly relate their differing views on the nature of light to different philosophical standpoints; namely the Copenhagen and the realist interpretations of quantum physics.

<PLACE FIGURE 1 HERE> 
The second discussion task concerns the concept of superposition and the 'Schrödinger's cat' thought experiment. It follows a short description of the main points in the thought experiment, based on our earlier research on students' understanding of 'Schrödinger's cat' (Myhrehagen \& Bungum, 2016). Results here showed that students were able to discuss the thought experiment in meaningful ways but needed more relevant resources to do so. We therefore included a short sequence on interpretations of quantum physics and the historical background of these, especially concerning superposition. The students were then given the following discussion task:

2. Discuss with a fellow student: What do you think about Schrödinger's cat? Is the cat both dead and alive before we open the box?

Both discussion tasks are challenging, as they concern philosophical aspects of quantum physics, where physicists still disagree. Clearly, the students do not have sufficient background to discuss the full depth of the questions. The questions are rather intended to introduce students to the philosophical dilemmas and different interpretations that quantum physics still entails, in line with the curriculum aims. The ReleQuant teaching material supports students in this endeavor by providing them with resources that display differing views as recommended by earlier research described above (see Bennett et al., 2010). The ReleQuant material does not take a stand in terms of interpretations of quantum physics, but rather invites students to reflect on quantum physics philosophically and to engage in the kind of discussions that physicists have had throughout history.

\section{RESEARCH METHODS}

\section{SAMPLE AND DATA COLLECTION}

This paper builds on data collected from trials of the ReleQuant teaching resources in March - May 2016, as part of the $4^{\text {th }}$ cycle of research-based development. Data are from 9 physics classes in 7 
upper secondary schools in Norway, comprising a total of 188 students in their final school year (1819 years old). These schools are regarded as having middle to high-achieving students in national comparison. Students were taught quantum physics by their regular teacher, using the ReleQuant online resources. Around two thirds of the students were male and the students were predominantly ethnic Norwegians with a small, mainly Asian minority. It is likely that Norwegian was a second language for some of the minority students. The teachers of these classes had attended at least a two-day seminar introducing the ReleQuant material, including lectures on quantum physics topics. No specific instruction was given concerning how to promote productive discussions. All students and teachers had consented to take part in the research project.

Small-group discussions were recorded by students on smart-phones and sent to their teacher, who forwarded them to the research team. The material consists of a total of 96 discussions, 55 on the wave-particle duality of light and 41 on Schrödinger's cat. Recorded discussions lasted from a few seconds up to 8 minutes. The lower number of recordings for the Schrödinger's cat discussion is caused by one of the schools failing to collect audio recordings for this discussion task.

Each discussion involved 2-3 students. In order to secure the students' anonymity we did not record students' names. Consequently, we cannot tell which students took part in both discussion tasks and which only took part in one of them. Assuming that most of the students that participated in the 41 Schrödinger's cat discussions also took part in one of the previous 55 wave-particle duality discussions, we can estimate that a total of 130 students contributed to the recordings that constitute the data material. The discrepancy from the 188 students that participated in the ReleQuant project comes from a combination of students absent from class when the task in question was given and students failing to either undertake the discussion task, record their discussions or to send the recordings to their teacher. This introduces a possible bias in the sense that discussions that were conducted but not sent to the teachers could be of poorer quality than those that were sent. Still, the data material as a whole represents a broad variation of student 
ability and teacher expertise, meaning that results are relevant to physics students in secondary school more generally.

\section{ANALYTICAL FRAMEWORK}

The framework for analysis of student discussions in our study has the categorizations formulated by Mercer (2004) described earlier in this paper as a starting point. The three categories of talk (disputational, cumulative and exploratory talk) are adjusted inductively based on our data analysis in two ways: Firstly, the category disputational talk is renamed to independent statements, taken to include student discussions that mainly consist of expressions of independent pieces of knowledge and viewpoints that do not build on each other. Mercer's term 'disputational' indicates a disagreement or even a conflict, while 'independent statements' signifies merely that students are not building on each other's utterances. Recordings containing only one single utterance are coded in this category.

Secondly, a new category was developed inductively from the student dialogues analyzed. This category, referred to as Confirmatory talk, involves students simply repeating or confirming what is said by their peer. In confirmatory talk, students relate to each other's utterances and express agreement with what is being said without bringing new ideas into the discussion.

Consequently, our conceptual framework for analysis consists of the following categories, where the order reflects increasing level of sophistication:

1. independent statements

2. confirmatory talk

3. cumulative talk

4. exploratory talk 
These four categories are then grouped as non-productive and productive discussions, respectively: Non-productive discussions include the categories independent statements (1) and confirmatory talk (2). In these dialogues, students may express a good grasp of physics knowledge, but the dialogue itself does not involve any joint knowledge generation. Productive discussions contain cumulative talk (3) and exploratory talk (4). These discussions are productive in the sense that students build on each other's utterances in a collaborative knowledge generation. Our use of the term 'productive' relates to interactional aspects, not the disciplinary content, hence it differs from how Engle and Conant (2002) use the term, referred to earlier in the paper. The disciplinary content is, however, investigated in a later section where we consider the products of productive small-group discussions. In the analysis, the categories are operationalized by use of characterizations of learning activities as active, constructive and interactive (Chi, 2009). For a discussion to be labelled cumulative, at least two students must participate constructively in the sense that they add new content to the dialogue. In exploratory discussions, the activity must in addition be interactive in the sense that at least one student engages in challenging and questioning what is being said.

\section{CODING}

All small-group discussions were fully transcribed and then coded by use of the ATLAS.ti software and the analytical framework. The coding was initially deductive using Mercer's three categories, and subsequently inductive in adjusting the categories in the analytical framework as described above. A discussion will naturally have segments of talk that fit with different categories. For example, a discussion may start in a confirmatory way and then turn into cumulative talk that also contains exploratory passages. Coding was hence first made on sequences of varying length, undertaken by the first author of this paper. This kind of coding does, however, not produce reliable results, since the unit of analysis is not well defined. A second coding with each discussion as the unit of analysis was therefore undertaken. One main category was assigned to each discussion, where "main" here 
means that the category captures the main characteristic of the discussion. This was possible since many discussions were rather homogenous with one dominating category. In this round, each discussion was coded independently by two researchers. When comparing the result of coding in main categories with the initial coding, we found that the frequency was higher for cumulative discussions and lower for confirmatory discussions. This makes sense since discussions that are mainly cumulative naturally contain sequences of confirmation.

The initial inter-coder reliability for the main categories after individual coding of two researchers was $74 \%$ (mismatch in 25 of 96 discussions). The disparity in coding was due to differing interpretations of discussion segments in terms of the codes, but also to differing evaluation of what was the dominating (main) code of discussions, especially for discussions of some length. After individual reconsidering of coding mismatches, 21 discussions were recoded and the inter-coder reliability rose to $96 \%$. The remaining discussions with divergent coding were resolved through discussions between all three researchers.

In addition to the coding in pre-defined categories described above, a thematic analysis (Braun \& Clarke, 2006) was undertaken in order to investigate more deeply the content of the discussions coded in the two categories "cumulative" and "exploratory", i.e. the discussions considered to be productive. This resulted in four broad themes that structure the presentation of results.

\section{ANALYSIS AND RESULTS}

\section{CHARACTERIZATION OF STUDENT DISCUSSIONS}

Quantitative results of the coding of main characteristics of student discussions are shown in Table 1.

The categories Independent statements, Confirmatory, Cumulative and Exploratory are grouped as non-productive and productive, and results are displayed for each of the two discussion tasks 
investigated. Results show that in total, $70 \%$ (67 of 96) of discussions were productive in the sense that they were characterized as cumulative or exploratory as a main characteristic. The fraction of productive discussions was higher in the discussions of Schrödinger's cat (78\%) than in the discussions on what light is (64\%).

\section{<PLACE TABLE 1 HERE $>$}

In the following, examples from the analysis within each main category of student discussions are presented. This is followed by presentation of the content in the discussions that were categorized as productive, considering the potential the discussions have for learning. We have chosen to give students consecutive numbers instead of pseudonyms. This signals that we focus on the joint understanding produced by the group rather than the individuals, and that we have not followed individuals or groups between the two discussions. We use pronouns 'he' or 'she' to refer to students in the discussions, with gender assertions drawn from their recorded voices.

\section{NON-PRODUCTIVE DISCUSSIONS}

\section{Discussions dominated by independent statements}

Many of the student dialogues categorized as independent statements consist of only one substantive utterance. For example, a recorded dialogue about the nature of light in a group of three students runs as follows:

Student 1 May light be both particles and wave?

Student 2 Yeah... light can be considered as both particle and wave. The basis for this way of thinking is that light is shown to have both wave properties and particle properties in different experiments. If light is sent through a double 
slit you get interference, interference pattern on a screen behind, which proves the wave properties of light. The light's particle properties are apparent in photoelectric effect where light can release particles from a metal surface when you send light at it. The requirements are that the light must have sufficiently short wave length and sufficiently high intensity.

\section{Student 1 Thank you.}

Student 2 shows good knowledge of the experimental evidence for particle and wave properties of light, but the group does not engage in a real discussion of what the duality of light means. The peers do not question or comment the utterance from student 2 . This may be due to the fact that it resembles what they can read in textbooks, and appears to give a "correct answer" to the question. This may reflect that physics students are used to, and may appreciate, physics as a subject where there are correct answers that are not to be questioned. This view of the subject may influence how students approach the task, and how they see the "discussion" as finished when one of them can come up with some answer that appears to be correct, even if the question given for the discussion is about how we can think of light as being both waves and particles.

\section{Confirmatory discussions}

Confirmatory discussions share some of the features of independent statements, but here students relate to their peer's utterance by confirming it, in the sense that they express agreement or repeat it. Here is one example of a discussion about light where there are interesting topics coming up in a student's utterance which are not developed since the discussion partner is merely confirming what is being said:

Student 3 (Reads the text in the task aloud) "Discuss with another student: Is it possible to think of light as being both wave and particle?" 
Student $4 \quad$ It should be possible since one explanation fits some situations, while the other fits better to other situations.

Student 3 We should use the explanation that fits best every situation.

Student $4 \quad$ Yes.

Student 3 But the question is really if it can be two things simultaneously. Or if it really is two different things. And light has the property that it changes at a given wavelength. Because they say that at shorter wavelengths, it is like a particle. It might be that there actually are wavelengths, but that the wavelengths become so small that it just looks like particles.

Student $4 \quad$ Yes.

Student 3 is here not completely happy with the idea that light behaves differently in different situations, and "We should use the explanation that fits best every situation" resembles universalism as an ideal feature of scientific theories and principles. This sequence has exploratory aspects, and leads to reflection about whether the two properties of light occur simultaneously or not. This has great potential for further reflection and learning, but the potential is not realized since Student 4 only offers confirmations. It is possible that Student 4 is not capable of bringing the discussion further, but it might also be that he is satisfied with arriving at some answer in order to finish the task. 


\section{PRODUCTIVE DISCUSSIONS}

\section{Cumulative discussions}

In cumulative discussions, the participants to a higher degree build on each other's utterances and formulate a joint basis of knowledge together. In this example about Schrödinger's cat, the students build a shared line of argumentation:

Student $5 \quad$ I think the cat is either dead or alive.

Student $6 \quad$ Yes, it cannot be both!

Student $5 \quad$ No

Student 6 It is like ice cream. Ice cream cannot be chocolate and vanilla. It might be vanilla with chocolate bits, or reverse. Do vanilla bits exist? But it cannot be chocolate and vanilla.

Student 5 To be dead and alive are really the strongest antonyms there are.

Student $6 \quad$ Yes.

Student 5 So I don't know, no, it is just...

Student 6 But like, the only thing that is for sure, is the cat really dead or alive before we open the box? No! We don't know whether the cat is dead or alive, that is the point, it is not both dead and alive.

Student 5 I agree. No, I don't understand. Is the cat both dead and alive before we open the box? It is not. It is either dead or it is alive.

\section{(...)}

Student 6 It is like, you don't know if you have got a good or bad grade, but it does not mean that you have got both. 
Student 5 No, and if you go home and I don't know whether you are at home or not, that does not mean that you are both home and on the way home.

Student $6 \quad$ We have disproved it.

Student 5 Yes. With this, we have falsified Schrödinger's...

Student 6 thought experiment.

The students here clarify their understanding of the Schrödinger's cat by referring to several examples from everyday life. The examples serve as support for the students' arguments and strengthen a joint line of logic where the main points are that (i) dead and alive are antonyms and a cat cannot be both, and (ii) the fact that we don't know which is the case does not mean that both is the case.

\section{Exploratory discussions}

In exploratory discussions, students question each other's statements in ways that may support the knowledge building by exposing a need for better understanding. The following transcript from a discussion about light illustrates this:

Student 7 Yes, uhm, the way I see it's like, the wave is just a representation of where it is most likely that the particle is, and that, there is a, the higher the wave crests and the lower the frequency, it means that there is more energy, which means there's a better chance of a photon coming ... being created.

Student $8 \quad$ Yes, sure, but, we're told that light moves like a wave.

Student $7 \quad$ Go on.

Student 8 Right? But I think of light as always a particle because it has mass, that is ... 
Student $7 \quad$ Light does not have mass.

Student 8 Yes, we've written that light has mass.

Student $7 \quad$ No, it's an energy.

Student 8 Yes, it's an energy, but there is a quantity in, under mass.

Student $7 \quad$ No, that's electrons.

Student 8 Should we do a search, we'll do a search on it. Light ...

The discussion is here interactive in the sense that both students challenge each other's utterances. Still, they encourage each other to keep at the argumentation. Student 7 starts with suggesting that the wave is only a representation of the probability of finding a particle. The student mixes up various wave concepts, but still the idea he expresses can be seen as resembling a wave function in quantum mechanics. Student 8 objects that "we are told" that light moves like a wave, but admits that he prefers to think of light as particles since it has mass. This evokes a need to find out whether it is correct that light has mass.

An example from discussions about Schrödinger's cat shows how an exploratory discussion may touch upon different aspects of the thought experiment without reaching any conclusion or formulation of a need to find answers to specific questions:

Student 9 (Reads the text in the task aloud) "What do you think about Schrödinger's cat? Is the cat both dead and alive before we open the box?"

Student 10 On this I share Einstein's view that the cat is not both dead and alive at the same time before we open the box, he is, or the cat is one or the other, it is just that we don't know which state it is in. 
Student 9 But isn't that what makes, the fact that we don't know, what makes it in a way both dead and alive?

Student 10 Yes, for the most part I agree with you, but at the same time, we are standing outside the box and we can't really know. For us it is ...

Student 11 Yes, as long as you're thinking to us it is alive.

Student 9 When we are standing outside the box, then it is dead and, but I don't know, alive, that doesn't fit for me.

Student 11 It has to do with the fact that that radioactive nucleus was both in state, two different states; emitted radiation and not emitted radiation, that thing that would ... that poison thing. And that once you measured, it was then that it sort of fell down to one of those states. That was the point.

At the outset, Student 10 seems to be confident in "sharing Einstein's view", but in the same sentence opens up for a different interpretation, namely that it is all about not knowing what state the cat is in. Student 9 then points to the possibility of unifying these two views (the fact that we don't know creates the interpretation of a dual state). This leads Student 11 to bring in the issue of relativism, that is, for whom the situation is seen, and then in the final quote two additional issues: the superposition of two possible states of the radioactive nucleus and the role of measurement in quantum physics. The discussion ends here (at least the students stopped the recording), possibly due to the level of confidence in Student 11's final argument where focus is transferred from the cat to the radioactive source. In fact, this final statement reflects a relatively mature understanding of superposition of quantum states and of the role of measurement. 


\section{PRODUCTS OF PRODUCTIVE SMALL-GROUP DISCUSSIONS}

In the foregoing we have presented examples of four categories of small-group discussions and characterized them as productive and non-productive respectively. The discussions coded as productive do not necessarily produce any valuable physics content, since 'productive' in the analysis is a characteristic of the interaction, not the content. The discussions are productive in the sense that students together construct or expose a view on the topics under discussion or lines of argumentation. In this section, we consider the products of these discussions in terms of potential for learning, and present results of qualitative analysis of the content of the student discussions coded as productive.

Three main patterns emerged from the analysis, capturing the broad functions that sequences of discussions may have for students' learning. These are: (i) articulating conceptual difficulties (ii) deepening understanding by exchange of views and (iii) developing new questions. In addition, we consider, in light of our empirical data, the question on whether small-group discussions may also contribute to students' developing or strengthening faulty conceptions in quantum physics.

\section{Articulating conceptual difficulties}

The discussions give students opportunities to articulate their conceptual difficulties within topics involved in the discussion task. The formulations of what students do not understand often seem to develop as a result of the discussion itself. This is explicit in the following sequence about Schrödinger's cat:

Student 12 No, I don't understand. Is the cat both dead and alive before we open the box? It is not. Either it is dead or it is alive.

Student 13 Yes, it is just that we don't know. The fact that we don't know doesn't mean that it is like this and this. That it is like this then. The fact that we don't 
understand ... no. I can't put it into words. But the fact that we don't know whether the cat is alive or dead does not mean that it is both.

After having stated difficulties in formulating the problem, Student 13 actually gives a very concise formulation of the difference between not knowing the cat's state and claiming that it is a superposition of the states 'dead' and 'alive'. This points to the essence of the discussion of how superposition should be interpreted in quantum physics, and the difference between Einstein's local 'hidden variable' theory and the Copenhagen interpretation (see Myhrehagen \& Bungum, 2016).

Another example of how student discussions involve articulation of difficulties shows that this does not always lead to a good conceptualization of the problem. Here, the students discuss whether light can be thought of as being both particles and waves:

Student 14 Yes, it is a really strange question. Do you mean, kind of, if it can be both at the same time?

Student 15 Yes, or I think that all light can be both ... I think what the task is after, is whether all light can be viewed as waves and particles in all situations.

Student 14 It can't be wave and particle at the same time when we define it.

Student $15 \quad$ What if it is particles in waves?

Student 14 Yes, but maybe it's something in between or maybe it is something in itself, right? But how can it be a particle and a wave? What if it is really that particle that has like wave ... what is it called? Wave ... movement.

\section{Student 15 Movement, yes.}

Student 14 It's not, I think. 
Student 15 No. Maybe it is something entirely new that we haven't been able to register. A new phenomenon that we haven't seen before.

The issue of simultaneity of wave/particle properties is here brought up, and the students consider how the wave-particle duality is to be interpreted: Does it mean that light is both wave and particle at the same time, or that it alternates between being wave and particle? The issue is highly relevant, but not resolved or clearly formulated by the students. Instead, the discussion then moves in direction of the well-known faulty novice conception that wave-particle duality implies a particle in a wave-shaped movement (see Olsen, 2002), before the students conclude that this is not the case. The last statement suggests that the students gave up considering light as wave or particle in the classical sense and concluded instead that it might be a new phenomenon altogether. That conclusion is quite sophisticated and resembles realist positions advocating that classical terms such as particle and wave should be abandoned in quantum physics altogether (Bunge, 2003). In this conversation, it is not necessarily a problem that the students considered the faulty particle in wavelike movement idea, since they appear to have used it as a stepping stone in their construction of their conclusion, which is more in line with expert conceptions. As argued by Smith, diSessa, and Roschelle (1993), novice ideas, although sometimes faulty, are pieces in students' complex processes of conceptual change.

\section{Deepening understanding by exchange of views}

Clearly, student discussions cannot produce completely new knowledge that the participants didn't bring into the discussion from previous knowledge. However, data from the study indicate that the discussions may contribute to deepening students' understanding by their mutual exchange of views. This is in particular the case in exploratory discussions, where students challenge each other's views. The following sequence from a discussion about Schrödinger's cat illustrates how the students manage to approach the problem from different angles through the discussion: 
Student 16 (Reads the text in the task aloud) «Discuss with another student: What do you think about Schrödinger's cat? Is the cat both dead and alive before we open the box?» What do you say?

Student 17 Uhm, both yes and no.

Student $16 \quad$ Because?

Student 17 The cat is in a way, it follows classical physics, right, because it is way too big, but it is just a way of showing how quantum physics works.

Student $16 \quad$ Because?

Student 17 In quantum physics you have spin, for example, right, and if you put an electron with spin in a closed box, for example, and then not, like, it is in superposition, right? You don't know if it is dead or alive.

Student 16 No.

Student 17 Schrödinger's cat is not, it would never happen. We could never measure it like they do in quantum physics, but it demonstrates the point of ...

Student 16 The point of quantum physics.

Student 17 The point of the thought experiment about Schrödinger's cat.

Student 16 Yes, I also think that what they are trying to do, is take quantum physics and turn it into the macro world, and it doesn't work that way because it concerns a radioactive material that was either one or the other, you don't know until you observe it or something like that. What happens is that it changes if something is emitted so that the poison bursts and the cat dies. In a way it is the same as an observation, I think. It is in a way, maybe we don't observe it directly, but in a way something in the universe does observe it 
because the cat dies, so the cat observes it. So I think it, in a way it collapses the thing.

Student 17 But I think you have misunderstood a bit. Because the thing with the Schrödinger experiment was that in the box, right, you had the cat and then you had the flask of poison and you have that quantum, or that atom ... radioactive thing. And the thing was that we can't with certainty measure exactly when the quantum state breaks down, right.

Student $16 \quad$ No.

Student 17 And sort of releases the poison and kills the cat. We don't know, we can't measure exactly when it is the case that the cat is both dead and alive without us knowing it, but it is in a way the same as ...

Student 16 It tries, in any case, to take quantum physics on a much larger ...

Student 17 And the observation thing ...

Student $16 \quad$ It doesn't work.

Student $17 \quad$... is in a way, it has something to do with us, not with the ... whether the flask of poison observes it, I was about to say. Or if that radioactive observes it. It is kind of like that saying that is ... If a tree falls down in the middle of the forest and no one is there to see it, has the tree fallen in the middle of the forest then? Has it happened if no one is there to observe it? You need an observer, right?

In the beginning of the sequence, Student 16 encourages his peer to elaborate on his description, which provides for exploration of the meaning of Schrödinger's thought experiment. The students touch upon several relevant physics issues: whether quantum physics applies to macroscopic systems such as a cat, whether superposition is only a way of describing an unknown state and 
whether observation in itself actually can determine the state of the quantum system (in physics terms: The collapse of the wave function). The students jointly develop an argument that changes the perspective of the observation; the cat can be an observer just as well as a human could. Student 17 then argues that following that line of reasoning, also the flask of poison could actually be considered to be an observer. This line of argument does not bring the students to any conclusion in the discussion as such, but it has evoked several dilemmas of importance for a deeper understanding of interpretations of quantum physics. It seems quite clear from the transcript that the issues students consider are products of the discussion and not something they had been considering beforehand.

\section{Developing new questions}

The discussions serve as an arena for students to develop new questions. The data material shows a range of new relevant questions coming up as results of student discussions. In the following example about light, the two students initially agree that it does not make sense that something can be both wave and particle. To explain why, student 18 initiates a description of the essential features of particles (photons) and waves, respectively:

Student 18 Because, kind of, photons are small packets of energy in a way, but waves ... that ... what is that, sort of, what kind of wave is it, is it just like propagation in, like, the particles in the room, kind of?

Student 19 Yes, that is just it.

Student 18 Or is it something else?

Student 19 How can like ...?

Student 18 How can it affect things in ...? 
Student 19 Sound waves make sense, but light waves don't quite make sense.

Student 18 Yes, because sound waves they vibrate and stuff, and the eardrum vibrates and ... all that there.

Student 19 Mhm.

Student 18 But there is no such membrane in the eye that in a way vibrates, no, I don't know, because of the light, kind of.

The intention was clearly to state the essential difference between particles and waves, but this argument is hindered when student 18 realizes that she is not sure about what kind of waves we are talking about when it comes to light. The student knows that waves have to do with movement, but for light she cannot tell what is moving. The student's awareness of this question is likely to be a product of the small-group discussion, since she seems rather confident at the outset of the discussion. The students seem to have no conception of what kind of movement the wave represents and through what medium the waves propagate. They make a comparison to sound, where they have more background knowledge, but they don't find any equivalent to the eardrum when it comes to seeing.

The parallel to sound is considered by several student groups, and in the following discussion students come up with the idea of a "sound particle":

Student 20 Yes, but it most often has particle properties when the wavelength is very small.

Student 21 Mhm, because then, then it could be gathered more in one.

Student 20 Yes, it is kind of, I don't know, the wave gathered more in one point in a way.

Student 21 Yes, yes, something like that. 
Student 20 What would be interesting to test is if you had a sound wave and a really, really small wavelength, and see if it behaved a bit like a particle, if you understand.

Student $21 \quad$ Mhm.

Student 20 That would've been interesting. They have probably tested it before, but, yeah.

Student 21 It does move in a medium.

The idea of waves with small wavelength being "condensed" to a point is possibly influenced by explanations by one of the physicists in the video in the ReleQuant resource. It resembles how we would visually perceive a typical wave drawing of a photon when the wavelength of a photon becomes so small that we cannot distinguish its wave shape. The idea of a "sound particle" comes up as Student 20 gets some associations based on the utterance from Student 21-, and again the questions students come up with seem to be a product of the discussion itself. The question of whether sound can show particle properties, in principle an interesting and relevant physics question, can hence be seen as a result of the discussion itself.

Do small-group discussions also contribute to faulty conceptions?

We have earlier shown how the conception of a particle in a wave-shaped movement comes up as an interpretation of the wave-particle duality in a student discussion. It is important to consider whether such faulty conceptions may be produced or strengthened as a product of the small-group discussions, in the sense that they are developed, consolidated or spread among students, without being challenged. 
The conception of a particle in a wave-shaped movement is touched upon in several discussions. For example:

Student 22 I somewhat agree that it is difficult to, in a way, a particle is delimited to a small area in space, and then it is difficult to consider that it can have a wavelength, since wavelength is something that spreads out.

(..)

Student 23 But, but you can in a way, if a particle moves like a wave then, then what comes after will sort of move one wavelength.

Student 22 Yes.

Student 24 Yes, I thought about that, too, in a way describe the path of the particle as a wave.

Student 23 Yes.

Student 22 Yes, that is possible...

Student 24 here expresses that she also has thought about the interpretation mentioned by Student 23. The way the discussion task is framed ("is it possible to think of...") in itself encourages to include the conception of a particle moving in a wave trajectory as one possible way of imagining light as both waves and particles. However, the fact that students mention wave-shaped particle movement does not mean that they necessarily hold this conception.

In the case of Schrödinger's cat discussions, an interpretation of superposition as simply a description of the state as unknown comes up in many student discussions. This statement from one of the students illustrates this:

Schrödinger's cat is a thought experiment about the fact that you can't know whether the cat is dead or alive until you have made measurements. It will be correct to say that the cat is 
both dead and alive before you make measurements, but the cat will be either dead or alive, only that you don't know until you check.

The view students present here is actually in line with Einstein's local 'hidden variable' interpretation of quantum physics (see Myhrehagen \& Bungum, 2016). This interpretation has been refuted by Aspect and other Bell test experiments (see Greca \& Freire, 2014), but the hidden variable idea is a reasonable intuitive conception to start at for novice learners of quantum physics given the classical, local realism of our macroscopic world. However, the quotation illustrates that the problem appears trivial to the students since they have no clear conceptions of differing interpretations of what superposition means in quantum physics.

\section{DISCUSSION}

By combining quantitative and qualitative analysis, our study has investigated students' small-group discussions in quantum physics and characterized them in terms of four categories, grouped as productive and non-productive discussions. We have then analyzed patterns for how a potential for learning is constituted in the productive discussions. We will here address whether the discussions are also productive from a disciplinary content point of view, how the potential for learning can be realized in the classroom and in what ways the specific teaching resources used in our investigation support productive disciplinary engagement.

The discussion tasks investigated in this paper deal with interpretative issues and philosophical aspects of quantum physics, and they hence deviate from what characterizes the traditional physics classroom, where there are clearly defined procedures for solving problems, little room for different opinions and an authority (textbook or teacher) that holds the correct answers (Carlone, 2003). The small-group discussions represent instead, in terms of the framework from Mortimer and Scott (2003), an interactive and dialogic approach where students are invited to interact with ideas and 
their peers' opinions and argumentation. The analysis shows that a majority of student discussions $(70 \%)$ in the data material are productive, in the sense that the students build on each other's utterances (cumulative discussions) or challenge and question what is said (exploratory discussions).

Are small-group discussions in physics also productive in building students' understanding of quantum physics? That is, is the use of small-group discussions worth-while in physics teaching? Through our analysis, we found that the productive discussions led students to articulate conceptual difficulties, deepen their understanding through exchange of views and formulate new questions. In line with how Vygotsky (1986) has described that thought comes into existence through language, this has a great potential for supporting students' development of understanding. Physics issues that came up in the small-group discussions we investigated were related to whether wave-particle duality of light is to be understood as two kinds of properties occurring simultaneously or not, what counts as an observer in quantum physics (in the case of Schrödinger's cat), and how light as waves should be understood, including whether sound waves can also be considered to be particles when the wavelength is short enough. Students' reflections on these issues may strengthen their understanding and motivation, and contribute to counteracting the fragmented understanding that research has shown that many students hold when their focus is on mastering the mathematical formalism of quantum mechanics (e.g. Johnston et al., 1998; Mahima \& Ritwick, 2017). Our results show that some of the small-group discussions have contents that relate to the nature of science more generally, such as what a model is and the ideal of universalism. This is further explored in a separate paper from the ReleQuant project (Henriksen, Angell, Vistnes, \& Bungum, submitted). The results indicate that attending to students' ontologies is essential when discussing interpretations of quantum physics, as also suggested by Baily and Finkelstein (2014). Höttecke and Silva (2011) have described how typical teacher-led communication patterns in physics lessons are among the obstacles for implementing history and philosophy as part of school physics. Extended use of smallgroup discussions in the teaching of quantum physics may hence also support the inclusion of the nature of science as content in school physics. 
How can the potential for learning provided by the small-group discussions best be realized? Students' learning outcome of small-group discussions is likely to depend on how the teacher uses the small-group discussions in a broader pedagogical frame. The small-group discussions represent the dialogic and interactive approaches that are often missing in traditional science teaching (Mortimer \& Scott, 2003). The recorded discussions suggest that the potential for learning created by some small-group discussions might be better realized by balancing students' own exploratory reflections in discussion tasks with the authoritative disciplinary content provided by the teacher. Such a balance is recommended by Scott et al. (2006), and confirmed in empirical research investigating the role of the teacher in students' collaborative knowledge building (Hmelo-Silver \& Barrows, 2008; Wang \& Buck, 2016; Ødegaard, Haug, Mork, \& Sørvik, 2014). Also teachers' metadiscourse as described by Tang (2017) may assist students in making connections between different parts of a conversation and model what it means to think as a scientist. In particular, the teacher's authoritative voice is crucial for dealing with faulty novice conceptions that students may consider during their small-group discussions, such as the conception of the wave-particle duality as a particle in a wave-shaped movement, which we saw signs of in the small-group discussions in this paper. Here, it is essential that the teacher recognizes how these conceptions may be used productively as resources for students' learning (Larkin, 2012; Smith et al., 1993). Further, it is clear from the transcribed discussions that students' understanding can be supported if the teacher points to how some students' reflections actually mirror various views that physicists hold about interpretations of quantum physics. Also, the challenges students encounter in interpreting what superposition means and describing light as a wave should be acknowledged as legitimate, in order for students to realize that they work with questions that are challenging even to professional physicists.

However, when using small-group discussions in a class, it is impossible for a single teacher to follow up every group at all times. The key points and questions that arise could instead be collected for discussion in the full class. The teacher can this way make the difficulties, questions and deepened 
insights that small-group discussions produce available for discussion with the entire class, providing for dialogic teaching as collective, reciprocal, cumulative and purposeful as described by Alexander (2006), and meet the criterion of holding students accountable to others and to shared disciplinary norms as described by Engle and Conant (2002). There is, however, a dilemma in that this stronger framing of the small-group discussions could restrict the freedom students feel in exploring various views on the rather challenging issues of the discussions.

It might be difficult for students to reformulate issues that come up in their discussions in a full class review, since their concepts and understanding are fragile and embryonic in the challenging kind of discussions analyzed in this paper. As pointed out by Sedova et al. (2014) and referred earlier in this paper, it can also lead to loss of interest by the other students when the teacher concentrate on the work of other groups than their own. Recordings of student discussions, which in this study were used for data collection for research, might therefore also serve as a tool for teachers in monitoring students' learning from discussions combined with the more authoritative approaches in full class.

It is important to take into account that not all students succeed in having productive discussions. The non-productive discussions analyzed in the present study indicate that some students may respond to the discussion tasks in the paradigm of the traditional physics classroom and merely search for clear-cut correct answers. In our data, these students appear to be content with reproducing textbook knowledge without elaborating on or questioning what it means. This resonates with how focus groups with ReleQuant project participants have shown that some students feel uncomfortable about the open discussions in physics lessons (Bøe et al., accepted). When using teaching resources like ReleQuant, where exploring meanings and philosophical dilemmas is a goal in itself, it is hence important that the teacher makes sure that this intention is understood by all students. Students could also be given a short instruction in how constructive questions may be asked in a discussion. 
The small-group discussions analysed in this study are clearly framed by the ReleQuant teaching resources as the pedagogical context. How do these resources support productive disciplinary engagement? In terms of the principles for supporting productive disciplinary engagement formulated by Engle and Conant (2002), these resources invite students to problematize content in terms of dilemmas in quantum physics and, to some extent, give them authority to formulate and address problems. The material also provides them with relevant resources, notably the video where physicists express differing views of what light is. The video gave students insight into different views on the discussion topic as recommended from earlier research (see Bennett et al., 2010). The principle of accountability, however, is not facilitated by the ReleQuant material itself, since students are not challenged to make their views assessable outside the small student groups. This is reflected in the lack of precision in many of the small-group discussions. On the other hand, a requirement of making results of the small-group discussions accountable to others might also diminish the opportunity the discussions provide for expressing a fragile and developing understanding.

\section{CONCLUSION}

Quantum physics challenges students' view of the physical world in fundamental ways, and research has shown that students' qualitative understanding is often weak (e.g. Hadzidaki, 2008). In a sociocultural perspective, knowledge is built by means of language (Vygotsky, 1986), and this study has therefore investigated small-group discussions in quantum physics and their potential for constructively enhancing students' learning. While working with teaching material developed in the ReleQuant project, students discuss dilemmas related to the wave-particle duality of light and the thought experiment about "Schrödinger's cat". These are topics where epistemological and ontological questions come into play in interpretations of what the theories mean on a fundamental level. They are therefore suited for a dialogic and interactive teaching approach that is often missing in science teaching (Mortimer \& Scott, 2003) and that deviates from the traditional physics classroom 
(e.g. Angell et al., 2004; Bøe et al., accepted). The study is based on specific learning material developed in the ReleQuant project and situated in the Norwegian curricular context. Still, the results have a wider relevance as the key features of the small-group discussion are not limited to this context.

Our study has demonstrated how Mercer's (2004) analytical framework can serve as a starting point for an empirically based modification of the framework to suit the analytical purpose at hand. The descriptions of student participation from Chi (2009) (active, constructive, interactive) were well suited for operationalization of the analytical categories. By use of the modified framework, the small-group discussions were grouped as productive and non-productive, respectively, and results indicate that a large proportion of the small-group discussions have potential for enhancing students' understanding and philosophical reflections in quantum physics. We found that this potential is constituted by leading students to (i) articulate conceptual difficulties, (ii) deepen their understanding through exchange of views and (iii) formulate new questions. In all these three ways, students are expressing their beginning understanding of very challenging subject matter, and the use of small-group discussions may this way contribute to a qualitative understanding that is often missing in students' conceptions of theories in quantum physics. Examples shown in this paper indicate that the small-group discussions themselves and the interaction they provide are important for generating the potential for learning, in the sense that they develop reflections, ideas or questions that students did not have beforehand.

The small-group discussions represent a dialogic discourse in terms of how Scott et al. (2006) have described the tension between authoritative and dialogic discourse in science teaching, and should be combined and balanced with the authoritative voice of the teacher. Our results show that students develop questions and lines of thought that the teacher could place in a broader frame in the classroom and thereby involve all students, also the ones who do not have productive discussions. This way, teachers can assist students in organizing the fragmented understanding they 
develop through the discussions and contribute with their own disciplinary insights, even if a final "correct answer" cannot always be provided. Precisely because there are clear disparities in how physicists interpret fundamental concepts and issues in quantum physics (see e.g. Cheong \& Song, 2014), this field is well suited for students also to gain insight into how interpretation and argumentation form part of the nature of science. With a sound balance with authoritative approaches, small-group discussions may contribute to students' motivation and understanding of quantum physics by making them aware of how their reflections on fundamental concepts and principles in quantum physics relate to physicists' interpretations of quantum physics today and historically. This way, small-group discussions represent a way of supporting students' meaningmaking in the challenging, but rewarding field of quantum physics.

\section{ACKNOWLEDGEMENTS}

This research has been supported by the Research Council of Norway, the Olav Thon Foundation and the Norwegian Centre for Science Education. We are grateful to participating teachers, students and colleagues in the ReleQuant research group for their contributions and collaboration. We also thank three anonymous reviewers for valuable feedback that has improved our paper.

\section{REFERENCES}

Alexander, R. (2006). Towards dialogic teaching: Rethinking classroom talk. Cambridge: Dialogos.

Andersson, J., \& Enghag, M. (2017). The relation between students' communicative moves during laboratory work in physics and outcomes of their actions. International Journal of Science Education, 39(2), 158-180.

Angell, C., Guttersrud, Ø., Henriksen, E. K., \& Isnes, A. (2004). Physics: Frightful, but fun. Pupils' and teachers' views of physics and physics teaching. Science Education, 88(5), 683-706. 
Ayene, M., Kriek, J., \& Damtie, B. (2011). Wave-particle duality and uncertainty principle: Phenomenographic categories of description of tertiary physics students' depictions. Physical Review Special Topics - Physics Education Research, 7(2), 020113.

Baily, C., \& Finkelstein, N. D. (2009). Development of quantum perspectives in modern physics. Physical Review Special Topics-Physics Education Research, 5(1), 010106.

Baily, C., \& Finkelstein, N. D. (2010). Teaching and understanding of quantum interpretations in modern physics courses. Physical Review Special Topics - Physics Education Research, 6(1), 010101.

Baily, C., \& Finkelstein, N. D. (2014). Ontological Flexibility and the Learning of Quantum Mechanics. arXiv preprint arXiv:1409.8499.

Bennett, J., Hogarth, S., Lubben, F., Campbell, B., \& Robinson, A. (2010). Talking science: The research evidence on the use of small group discussions in science teaching. International Journal of Science Education, 32(1), 69-95.

Braun, V., \& Clarke, V. (2006). Using thematic analysis in psychology. Qualitative Research in Psychology, 3(2), 77-101.

Bunge, M. (2003). Twenty-Five Centuries of Quantum Physics: From Pythagoras to Us, and from Subjectivism to Realism. Science \& Education, 12(5), 445-466. doi:10.1023/a:1025336332476

Bunge, M. (2012). Does Quantum Physics Refute Realism, Materialism and Determinism? Science \& Education, 21(10), 1601-1610. doi:10.1007/s11191-011-9410-Z

Bungum, B., Henriksen, E. K., Angell, C., Tellefsen, C. W., \& Bøe, M. V. (2015). ReleQuant - Improving teaching and learning in quantum physics through educational design research. NorDiNa, 11(2), 153-168.

Bungum, B., Manshadi, S., \& Lysne, D. A. (2014). Mathematical speech and practical action: a case study of the challenges of including mathematics in a school technology project. International Journal of Mathematical Education in Science and Technology, 45(8), 1131-1145. doi:10.1080/0020739X.2014.914253

Bungum, B., \& Tellefsen, C. W. (2016). Bruk av språk og diskusjoner for å fremme elevers forståelse i kvantefysikk gjennom digitale ressurser. 2016, 2(1). doi:10.17585/ntpk.v2.127

Bøe, M. V., Henriksen, E. K., \& Angell, C. (accepted). Actual vs. implied physics students: How students from traditional physics classrooms related to an innovative approach to quantum physics. Science Education.

Carlone, H. B. (2003). Innovative science within and against a culture of "achievement". Science Education, 87(3), 307-328. doi:10.1002/sce.10071

Carlone, H. B. (2004). The cultural production of science in reform-based physics: Girls' access, participation, and resistance. Journal of Research in Science Teaching, 41(4), 392-414.

Cheong, Y. W., \& Song, J. (2014). Different Levels of the Meaning of Wave-Particle Duality and a Suspensive Perspective on the Interpretation of Quantum Theory. Science \& Education, 23(5), 1011-1030. doi:10.1007/s11191-013-9633-2

Chi, M. T. H. (2009). Active-Constructive-Interactive: A Conceptual Framework for Differentiating Learning Activities. Topics in Cognitive Science, 1(1), 73-105. doi:10.1111/j.1756-8765.2008.01005.x

Chi, M. T. H., \& Menekse, M. (2015). Dialogue patterns in peer collaboration that promote learning. In L. B. Resnick, C. Asterhan, \& S. Clarke (Eds.), Socializing Intelligence Through Academic Talk and Dialogue (pp. 263-274): American Educational Research Association. 
Chi, M. T. H., Roy, M., \& Hausmann, R. G. M. (2008). Observing Tutorial Dialogues Collaboratively: Insights About Human Tutoring Effectiveness From Vicarious Learning. Cognitive Science, 32(2), 301-341. doi:10.1080/03640210701863396

Cini, M. (2003). How Real is the Quantum World? Science \& Education, 12(5), 531-540. doi:10.1023/a:1025326012905

Cordero, A. (2003). Understanding Quantum Physics. Science \& Education, 12(5), 503-511. doi:10.1023/a:1025366723885

Enghag, M., Gustafsson, P., \& Jonsson, G. (2007). From everyday life experiences to physics understanding occurring in small group work with context rich problems during introductory physics work at university. Research in Science Education, 37(4), 449467.

Engle, R. A., \& Conant, F. R. (2002). Guiding Principles for Fostering Productive Disciplinary Engagement: Explaining an Emergent Argument in a Community of Learners Classroom. Cognition and Instruction, 20(4), 399-483. doi:10.1207/S1532690XCI2004_1

Fischler, H. R., \& Lichtfeldt, M. (1992). Modern Physics and Students Conceptions. International Journal of Science Education, 14(2), 181-190.

Forge, J. (2003). Sharp and Blunt Values. Science \& Education, 12(5), 479-493. doi:10.1023/a:1025373911997

Freire, O. (2003). A Story Without an Ending: The Quantum Physics Controversy 1950 1970. Science \& Education, 12(5), 573-586. doi:10.1023/a:1025317927440

Greca, I. M., \& Freire, O. (2003). Does an emphasis on the concept of quantum states enhance students' understanding of quantum mechanics? Science \& Education, 12(5), 541-557.

Greca, I. M., \& Freire, O. (2014). Teaching introductory quantum physics and chemistry: caveats from the history of science and science teaching to the training of modern chemists. Chemistry Education Research and Practice, 15(3), 286-296. doi:10.1039/c4rp00006d

Hadzidaki, P. (2008). 'Quantum Mechanics' and 'Scientific Explanation' An Explanatory Strategy Aiming at Providing 'Understanding'. Science \& Education, 17(1), 49-73. doi:10.1007/s11191-006-9052-8

Haroche, S. (2013). Nobel Lecture: Controlling photons in a box and exploring the quantum to classical boundary. Reviews of Modern Physics, 85(3), 1083-1102.

Henriksen, E. K., Angell, C., Vistnes, A. I., \& Bungum, B. (in press). What is light? Students' reflections on the wave-particle duality of light and the nature of physics Science \& Education.

Henriksen, E. K., Angell, C., Vistnes, A. I., \& Bungum, B. (submitted). What is light? Students' reflections on the wave-particle duality of light and the nature of physics. Submitted to Science \& Education.

Hmelo-Silver, C. E., \& Barrows, H. S. (2008). Facilitating Collaborative Knowledge Building. Cognition and Instruction, 26(1), 48-94. doi:10.1080/07370000701798495

Home, D., \& Whitaker, A. (2007). Einstein's struggle with quantum theory. A reappraisal.: Springer.

Howe, C., \& Abedin, M. (2013). Classroom dialogue: A systematic review across four decades of research. Cambridge Journal of Education, 43(3), 325-356.

Höttecke, D., \& Silva, C. C. (2011). Why implementing history and philosophy in school science education is a challenge: An analysis of obstacles. Science \& Education, 20(34), 293-316. 
Johnston, I. D., Crawford, K., \& Fletcher, P. R. (1998). Student difficulties in learning quantum mechanics. International Journal of Science Education, 20(4), 427-446. doi:10.1080/0950069980200404

Kalkanis, G., Hadzidaki, P., \& Stavrou, D. (2003). An instructional model for a radical conceptual change towards quantum mechanics concepts. Science Education, 87(2), 257-280.

Kirschner, P. A., Sweller, J., \& Clark, R. E. (2006). Why Minimal Guidance During Instruction Does Not Work: An Analysis of the Failure of Constructivist, Discovery, Problem-Based, Experiential, and Inquiry-Based Teaching. Educational Psychologist, 41(2), 75-86. doi:10.1207/s15326985ep4102_1

Kragh, H. (2002). Quantum Generations: A History of Physics in the Twentieth Century. Princeton NJ: Princeton University Press.

Krijtenburg-Lewerissa, K., Pol, H. J., Brinkman, A., \& van Joolingen, W. R. (2017). Insights into teaching quantum mechanics in secondary and lower undergraduate education. Physical Review Physics Education Research, 13(1), 010109.

Larkin, D. (2012). Misconceptions about "misconceptions": Preservice secondary science teachers' views on the value and role of student ideas. Science Education, 96(5), 927959. doi:10.1002/sce.21022

Lautesse, P., Vila Valls, A., Ferlin, F., Héraud, J.-L., \& Chabot, H. (2015). Teaching Quantum Physics in Upper Secondary School in France: 'Quanton' Versus 'WaveParticle' Duality, Two Approaches of the Problem of Reference. Science \& Education, 24(7), 937-955. doi:10.1007/s11191-015-9755-9

Lemke, J. L. (1990). Talking science: Language, learning, and values: ERIC.

Lyle, S. (2008). Dialogic Teaching: Discussing Theoretical Contexts and Reviewing Evidence from Classroom Practice. Language and Education, 22(3), 222-240. doi:10.1080/09500780802152499

Mahima, C., \& Ritwick, D. (2017). Quantum mechanical wavefunction: visualization at undergraduate level. European Journal of Physics, 38(1), 015404.

Mercer, N. (2004). Sociocultural discourse analysis: Analysing classroom talk as a social mode of thinking. Journal of Applied Linguistics, 1(2), 137-168.

Mortimer, E. F., \& Scott, P. H. (2003). Meaning Making in Secondary Science Classrooms. Maidenhead, Philadelphia: Open University Press.

Myhrehagen, H. V., \& Bungum, B. (2016). 'From the cat's point of view': upper secondary physics students' reflections on Schrödinger's thought experiment. Physics Education, 51(5), 055009.

NDET. (2006). Physics - programme subject in programmes for specialization in general studies. Retrieved April 2017 from https://www.udir.no/kl06/FYS1O1?lplang=http://data.udir.no/kl06/eng. Oslo: Norwegian Directorate for Education and Training.

Olsen, R. V. (2002). Introducing quantum mechanics in the upper secondary school: A study in Norway. International Journal of Science Education, 24(6), 565-574. doi:10.1080/09500690110073982

Pospiech, G. (2000). Uncertainty and complementarity: the heart of quantum physics. Physics Education, 35(6), 393.

Schwartz, D. L. (1995). The emergence of abstract representations in dyad problem solving. The journal of the learning sciences, 4(3), 321-354.

Scott, P., Mortimer, E., \& Aguiar, O. (2006). The tension between authoritative and dialogic discourse: A fundamental characteristic of meaning making interactions in high school science lessons. Science Education, 90(4), 605-631. 
Sedova, K., Salamounova, Z., \& Svaricek, R. (2014). Troubles with dialogic teaching. Learning, Culture and Social Interaction, 3(4), 274-285.

Singh, C. (2008). Interactive learning tutorials on quantum mechanics. American Journal of Physics, 76(4), 400-405.

Smith, J. P., diSessa, A. A., \& Roschelle, J. (1993). Misconceptions reconceived: A constructivist analysis of knowledge in transition. The journal of the learning sciences, 3(2), 115-163.

Tang, K. S. (2017). Analyzing Teachers' Use of Metadiscourse: The Missing Element in Classroom Discourse Analysis. Science Education, 101(4), 548-583. doi:doi:10.1002/sce.21275

Vygotsky, L. (1986). Thought and language. Cambridge, MA: MIT Presss.

Wang, J., \& Buck, G. A. (2016). Understanding a High School Physics Teacher's Pedagogical Content Knowledge of Argumentation. Journal of Science Teacher Education, 27(5), 577-604. doi:10.1007/s 10972-016-9476-1

Ødegaard, M., Haug, B., Mork, S. M., \& Sørvik, G. O. (2014). Challenges and support when teaching science through an integrated inquiry and literacy approach. International Journal of Science Education, 36(18), 2997-3020. 


\section{CAPTIONS:}

Figure 1. Small-group discussion task about the wave and particle nature of light.

Table 1. Main characteristics of student discussions.

Table 1

\begin{tabular}{|c|c|c|c|}
\hline & $\begin{array}{c}\text { Discussions on } \\
\text { light }\end{array}$ & $\begin{array}{l}\text { Discussions on } \\
\text { Schrödinger's cat }\end{array}$ & Total \\
\hline Non-productive, total & 20 & 9 & 29 \\
\hline Independent statements & 10 & 4 & 14 \\
\hline Confirmatory & 10 & 5 & 15 \\
\hline Productive, total & 35 & 32 & 67 \\
\hline Cumulative & 28 & 20 & 48 \\
\hline Exploratory & 7 & 12 & 19 \\
\hline Total & 55 & 41 & 96 \\
\hline $\begin{array}{l}\text { Proportion productive } \\
\text { discussions }\end{array}$ & $64 \%$ & $78 \%$ & $70 \%$ \\
\hline
\end{tabular}

